\title{
Contemporary Art in Heritage Spaces
}

\section{Edited by Nick Cass, Gill Park, and Anna Powell}

First published 2020

ISBN: 978-0-367-I4805-8 (hbk)

ISBN: 978-0-429-05349-8 (ebk)

Chapter 9

\section{Expanded Interiors}

Bringing contemporary site-specific fine-art practice to Roman houses at Herculaneum and Pompeii

Catrin Huber 


\section{Expanded Interiors}

\section{Bringing contemporary site-specific fine-art practice to Roman houses at Herculaneum and Pompeii}

\section{Catrin Huber}

\section{Introduction}

This chapter gives an insight into the methods and dialogue-based nature of Expanded Interiors, an interdisciplinary, practice-led, AHRC-funded research project. Expanded Interiors created a unique dialogue between two historically distinct elements: contemporary fine-art practice and some carefully chosen ancient Roman wall paintings: architectural remains found within the UNESCO World Heritage sites at Herculaneum and Pompeii.

The dialogue-based nature of Expanded Interiors was a means through which to critically reflect upon historical and contemporary practice simultaneously. Dialogue was also an important element in the intersected research of the artists and archaeologists working on the project. For this reason, dialogue is the defining element of the following text, parts of which utilise fictional conversations between historical artists. These fictional discussions allow me to situate Roman wall painting within a discourse of critical spatial practice, highlighting three distinct historical positions (one from $50 \mathrm{bc}$, two from the twentieth century) that, I argue, are crucial for installation practice. Each position explores the intersections of art, architecture, and life, while highlighting a different aspect of Roman art practice. This fictional conversation with the Roman wall painter allows me to inhabit these various positions, enabling me to scrutinise historical and contemporary making from several perspectives. It facilitates an intersecting of practices, something which was at the core of my practice-led investigation of these Roman houses and their wall paintings.

My chapter has seven sections, each of which provides a different perspective on, and a different voice for the project. After some introductory insight into the study's origins, a critical discussion regarding the relevance of Roman wall painting for contemporary fine-art practice outlines a context for Expanded Interiors. Some general information about the Expanded Interiors project is then followed by examples of interdisciplinary artist/archaeologist dialogue. Finally, I discuss the specific installations at the House of the Beautiful Courtyard and the House of the Cryptoporticus, and their heritage 
site context. The chapter concludes by rejoining the participants of the initial fictional forum, allowing them a final say.

\section{What inspired Expanded Interiors?}

In 2008, visiting Herculaneum, Oplontis, and Pompeii for the first time, I was struck by the extraordinary vibrancy and complexity of Roman wall paintings. Seeing them in situ, they seemed like works from the future, not the past. Their freshness seemed vital; wholly relevant to contemporary installation art, and to site-responsive and critical spatial practice in particular.

Roman wall paintings and heritage sites also had a particular relevance for my own wider artistic practice. As a (mostly) abstract painter and installation artist, I was interested in how to integrate (or make permeable) paintings within specific architectural settings, be it on a formal or conceptual level. I was interested, too, in how to make paintings define spaces, in how to 'activate' viewers, and in how perspectival systems might open up walls or spaces. I had previously explored combining different visual languages within painting installations, and Roman wall painting seemed to offer some fresh, radical, and unusual approaches to all of the above. The intersection of contemporary and Roman wall painting proved especially fruitful regarding the widening of critical and creative possibilities. It was this close dialogue between specific Roman wall paintings, Roman houses, and Roman practice that facilitated my exploration of historical practice's relevance for contemporary making. The dialogues that ensued facilitated a different, practice-led perspective on, and interpretation of, this historical practice.

Admittedly, I view these Roman works through a contemporary lens, but I believe re-evaluation of these specific historical practices through contemporary making can inspire fresh methodologies for current and future practice. Initially, my fascination with Roman wall painting resulted in a series of site-responsive exhibitions developed at a range of venues including the British School at Rome, the Hatton Gallery in Newcastle, and Kiosk24 in Herford, Germany.

\section{A performance: dialogue with a woman Roman wall painter from antiquity}

Since 2008, I have used an evolving fictional dialogue between an unnamed woman Roman wall painter and a revolving cast of what I consider relevant historical artists as a means through which to explore Roman wall painting's significance for contemporary practice. This dialogue has usually been performed in conjunction with a slide projection as I voice the different characters' thoughts. I function as the chair and, currently at least, the other guests are El Lissitzky, the Russian avantgarde artist who wanted to merge art and life, and Kurt Schwitters, the Merz artist who famously took 
over his parents' Hanover apartment with his Merzbau. Both Lissitzky and Schwitters are key figures in the history of installation art, and each adopts a distinct position as the imagined discussion unfolds. Some of Lissitzky's exhibition designs (for example Proun Room, 1924; Kabinett der Abstrakten, 1926) emphasised activation of the walls, and aimed at redefining spaces for an activated visitor experience. Meanwhile Schwitters ultimately became more and more appreciated for his Merzbauten and Merzbarn, for his artistic interventions, transformations, and reinterpretations of architectural, mostly interior spaces.

Both artists, in their different ways, have helped expand and redefine interior space on both formal and conceptual levels, and crucially, this is what links them, in this work, to the work of the Roman wall painter. I argue that they offer enriching new perspectives on Roman wall painting. Incorporating an emphatic inhabiting, my fictional responses are derived from thorough research into each artist's respective practices. Here, by way of example, is a dialogue extract:

RW (WOMAN ROMAN WALL PAINTER) Our work impacts upon you, the viewer, physically. Imagine being immersed in these paintings. We realised them in such a way that the viewing inhabitants animated an imagined environment, they themselves constituting a missing link in the chain. Representation became a concrete physical experience, yet also enabled you to become part of the dream.

EL (EL LISSITZKY) Interesting! In my Proun and Demonstration Rooms, I, too, activated the viewer. However, it wasn't just the viewer - the whole room was activated; animated by the movement of the perceiver. [...]

My standardised system could activate any room, always accentuating the independence of the individual artworks within. I thought this economical and revolutionary with reference to exhibition design and concept, and rather elegant, too. It was not based on fantasy and illusion, but on the concrete reality of materials and the present. It wasn't meant to lure you into a world of dreams; it was meant to highlight the need for active participation in this world.

RW Well, ingeniously, we combined imagination and reality. The magical power of representation stimulated the imagination, but we also highlighted the act of viewing and created an awareness of the physical nature of painting. Further, our wall paintings aimed to nourish the viewer's intellect. These painted architectures were as much temples and palaces as they were mathematical riddles and challenges. Mr Lissitzky, please don't underestimate us Roman painters! We were highly ambitious and wanted to engage the perceptive viewer in a game of hide and seek.

KS (KURT SCHWITTERS) Activation of the viewer you say, Mr Lissitzky! The viewer is a missing link in the chain, you say, Roman wall paintress! What 
about the rest of the world? What about the environment? What about our fellow living creatures who are not human beings? I invited a family of hamsters into my Merzbau. They loved the grottos and interlocking cubes, used the rib features to slide down, and nested and reproduced elsewhere. I studied what they liked, where they could nest and what they might miss, and temporarily adjusted my designs accordingly. Did they inhabit the environment as happily as I did? Perhaps. Or maybe not quite. But how could I really know? My point is this: whom should one think of when intervening or making architecture? Why focus only on humans? And to come back to what you said earlier Mr Lissitzky: this is the bigger picture!

EL (Laughing) Ok, so Kurt builds for hamsters. But you, madam: weren't you just painting walls as if painting a wooden board? The scale was different, but what, exactly, constituted your intervention into architecture?

RW The magic lay in the balance between imagined and physical architecture; the way in which wall paintings immersed the viewer in their surroundings. Nor should you think only in terms of an individual room. Our wall paintings reflected the different roles and functions of the various rooms in which they appeared. They formed a system that shaped and articulated the Roman House. Our wall paintings structured the house, making it navigable and understandable for visitors. They were much more than panel paintings.

EL I must say that you have a point there, madam. But can anything of value for twenty-first-century painting be gleaned from your work? A fresh approach? Some revolutionary zest, perhaps?

Above, El Lissitzky raises some important questions on my behalf. Within the performance, the woman Roman wall painter responds to his queries by describing how buildings articulate power relationships, and how Roman wall painting as a 'site-defining' practice (my terminology) contributes to this. She also points out that Roman painting workshops were very well organised, and that this might be something for the contemporary practitioner to consider. I use the term 'site-defining' because some Roman wall paintings clearly determined the house with reference to 'public' and 'private' spaces, as well as the role and function of rooms. I am also exploring what 'site-defining' could mean in a contemporary practice context, and whether it facilitates a more radical rethinking of site-specific work.

While these imagined conversations and subsequent reading performances helped me to draw out the wider context of possible relations between Roman wall painting and contemporary fine-art practice, it became clear that, in order to understand these works and practices in more depth, I would need to be in situ, investigating specific wall paintings in specific Roman houses. Interdisciplinary exploration and discussion would also be key, and this eventually led to Expanded Interiors, the framework of which I will outline below. 


\section{Expanded Interiors: framework and some key information}

For Expanded Interiors, I brought together an interdisciplinary research team of fellow staff members at Newcastle University. This comprised archaeologists Professor Ian Haynes (our Co-Investigator) and Dr Thea Ravasi (our Archaeology Research Assistant); our digital technology expert Alex Turner; and artist Rosie Morris (our Fine Art Research Assistant). I myself was the project's Principle Investigator. Together, we investigated the House of the Beautiful Courtyard at Herculaneum and the House of the Cryptoporticus at Pompeii. The project was a partnership between the Parco Archeologico di Ercolano, the Herculaneum Conservation Project, the Parco Archeologico di Pompeii, and Newcastle University.

The two Roman houses we chose were perfect for Expanded Interior's investigation for a number of reasons. Firstly, each house has a very distinctive layout. At the House of the Cryptoporticus, there is a rare (for town-houses) underground passageway and bath complex, while the House of the Beautiful Courtyard has an unusually large (for its time) reception room. Secondly, these two houses have strongly contrasting physical qualities and distinct private and public functions, and, consequently, they are each adorned with particular and mutually exclusive types of wall paintings. At the House of the Cryptoporticus, we worked with two different types of exquisite, recently restored, second-style Roman wall paintings: an unfolding frieze as part of a painted colonnade, and an illusionistic architectural work which transforms the room in which it is contained. At the House of the Beautiful Courtyard, meanwhile, we explored a less well-preserved room which was predominantly decorated in the late third style. It was important that all of these wall paintings used painted architectural structures to embed the works within their physical surroundings. However, the artistic strategies through which the Roman painters achieved this - and through which their paintings engage the viewer - are different in each instance. This allowed us to study a breadth of artistic strategies while facilitating different contemporary artistic responses.

Our investigation of these houses involved thorough research, both literature-based and archival. This was combined with direct archaeological and artistic site study, and with artistic practice. The archaeological research focused on archival, historical, and archaeological analysis of the houses, with an emphasis on analysis of the surviving wall paintings in relation to the buildings' architecture and design, and a focus on light, access, and movement. For the artistic exploration, I was particularly interested in analysing, through photography and drawing, the specifics of each respective Roman wall painting, and the way in which it was integrated into its actual space. I paid close attention to artistic decisions regarding two-dimensional and three-dimensional space (composition, perspective); open and closed walls; multiple ways of integrating imagery and/or encoding meaning (for 
example propaganda images); the colour and light relationship with the surrounding room/building; and the movement of the viewer.

For the wall paintings at the House of the Cryptoporticus, a range of interpretations were already available for study (for example Blazeby's detailed visual and spatial analysis of one room at Casa del Criptoportico, House of the Cryptoporticus, for the Skenographia Project). ${ }^{1}$ But looking at these paintings from a contemporary practice perspective offered a new approach and new insights into the paintings' sophisticated means (see discussion below).

These initial drawings and photographs formed part of the source material for the testing of the above-mentioned strategies of Roman wall paintings through and for contemporary practice. This was achieved through an experimental, creative approach incorporating drawing, photography, collage, painting, and the use of three-dimensional models. I also tested various potential interactions between replicas of artefacts, Roman wall painting, and contemporary wall paintings, again using photography, collage, painting, and three-dimensional models. Three-dimensional experimentation with replica (for example scale, material) was part of the process. This helped to highlight certain aspects of the original artefacts, while simultaneously dislodging them (via replicated versions) from their original context. This extensive, intensive research process culminated in the development of three new installations spread between the two Roman houses.

\section{Artists and archaeologists}

Some of the most interesting ensuing dialogue between artists and archaeologists happened during site visits. To be in the actual physical spaces exploring the entanglement of Roman wall paintings and the houses' architecture was hugely exciting, but it was also then that our observations and interpretations of the evidence around us sometimes tended to differ. I used one such discussion, albeit loosely, as a starting-point for further imagined dialogue with my fictional woman Roman wall painter:

RW But why, Catrin, are you, a twenty-first-century artist, referring back to the ancient creations of my workshop?

$\mathrm{CH}$ Because I am struck by the incredibly intricate nature of your work; its interplay of different visual languages and its encoded messages. And by the different ways your paintings were designed to respond to given architectural situations and the role and function of rooms. Studying your work, one discovers many surprising idiosyncrasies.

RW 'Surprising idiosyncrasies?'

$\mathrm{CH}$ Well, let's take the colonnade and Trojan frieze in the House of the Cryptoporticus, for example. One expects their composition to be symmetrically aligned, as art historians and archaeologists often point out that this characteristic is typical of second style Roman wall 
painting. However, one soon realises that the distances between the Cryptoporticus's windows are irregular, hence your design had to be adjusted accordingly. And according to drawings by Spinazzola, ${ }^{2}$ the archaeologist who excavated the house from 1911-1914, this happened in a regular and logical way. I was surprised, however, that looking at the wall paintings today, they don't really align to Spinazzola's drawings, at least not in the west wing of the house. Instead, they follow a much more illogical, irregular structure. This - together with the surprising chronology, and your apparent interpretations of scenes within the frieze itself - fascinates me.

As a practitioner it makes absolute sense! How else to deal with such a long corridor? A regular, symmetrical scheme would lack dynamism and movement and become boring and repetitive on such a large scale. But this subtle, underlying subversion of its own principles keeps these paintings fresh, capturing the viewer. Plus this approach arguably chimed with the role and function of the cryptoporticus, encouraging the viewer to stroll while also grabbing their attention via its 'surprising idiosyncrasies.'

RW Interesting! But might that overemphasise the notion of irregularities as a pre-planned concept? We worked in teams, remember, and quickly. On such a large-scale project, not everyone worked in perfect synchronisation or entirely according to plan. That said, we did of course aim to make the works as stimulating, multi-layered, and surprising as possible. If finances allowed, a tailor-made response to each different house was crucial to our endeavour and something we were very proud of.

The extent of the irregularity in this highly repetitive system was indeed surprising, and intrigued both artists and archaeologists. It was the question of how best to interpret one aspect of the painted colonnade in the Cryptoporticus, however, which drove a good-natured wedge between the archaeologists and the artists. The colonnade is organised as a sequence of painted herms - painted statues as part of narrow pillars often portraying Hermes. The wall between the herms is - according to the archaeologists divided into a sequence of panels, with a meander motif at the bottom, painted in perspective, and a series of horizontal bands at the top. Between the heads of the herms runs the Trojan frieze depicting scenes from The Iliad and The Aethiopis.

Both artists, Rosie Morris and myself, were intrigued by the irregular spacing of the bands that frame the panels on the wall between the herms. When walking along the Cryptoporticus these irregular bands between the panels acted more like regular columns on a building seen in motion from different viewpoints. Consequently, we artists interpreted them as pillars set in front of another receding wall, rather than as panels framed by bands.

While this might sound like a somewhat moot disagreement over terms, I would argue that the interpretation provided by Rosie and me changes 
perceptions of the colonnade quite substantially, since it facilitates a different understanding of how the painters used or hinted at perspective (lived perspective; not scientific), while activating the space and creating rhythm. I believe this use of a multi-layered structure within the colonnade scheme facilitates a dynamic interaction of fictional and real space, allowing for a changing interaction between the viewer and the painting/Cryptoporticus space. It can give the viewer or user of the space a heightened awareness of their own movement, and thus affect their perception. The painting seems mindful of a person moving through space.

From an artist's point of view, this is interesting when considering Roman wall painting as a practice that brings together and works with plural images rather effectively. ${ }^{3}$ Roman wall painting (second style onwards, at least) regularly juxtaposes different types of images and visual languages - hierarchies of images - which are usually organised within a painted architectural framework or several interconnecting ones. The gaps, formal and content-wise, inbetween and within images, in terms of what is being told, not told, or told differently, become incredibly potent, these aspects structured and highlighted by the architectural framework.

For the contemporary artist, this Roman approach is powerful. It resonates when considering how images might be organised within a contemporary context, raising the following questions:

1 Might it facilitate different ways of working with plural images?

2 How can plural images be used in a variety of ways to dismantle their own 'meaning making'?

3 How can abstraction or painted structures be used to organise or disrupt spaces?

4 How might we merge different perspectival or a-perspectival systems to heighten awareness of space and the present-ness of the viewer?

These considerations were pertinent when developing my installations at the House of the Beautiful Courtyard in Herculaneum and at the House of the Cryptoporticus in Pompeii (see discussion below).

\section{Expanded Interiors at the House of the Beautiful Courtyard in Herculaneum, and the House of the Cryptoporticus in Pompeii}

Reflecting on the dialogical nature of the installations, and exploring their relationships with the heritage site, I returned to the fictional dialogue with the woman Roman painter. In order to do this, we reconvened in the grand reception room at the House of the Beautiful Courtyard, where my exhibition was still on display. 


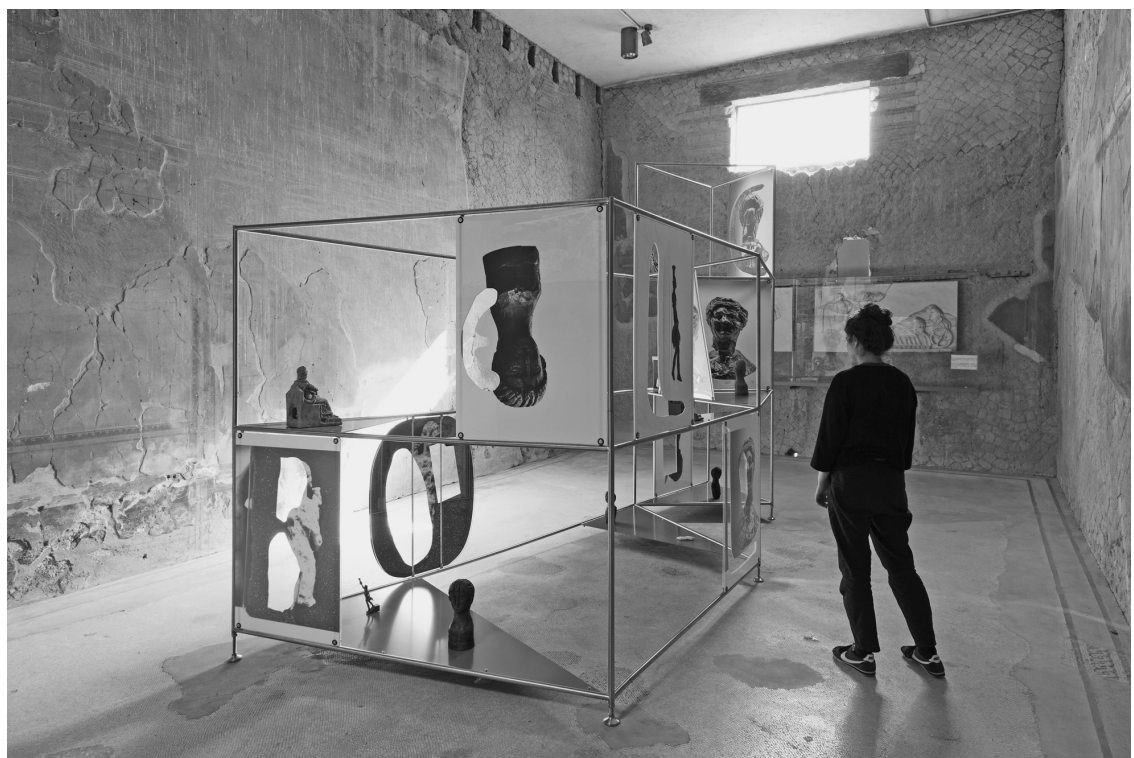

Figure 9.I Expanded Interiors at Herculaneum. Image credit:Amedeo Benestante. Courtesy of Ministero dei Beni e delleAttività Culturali e del Turismo - Parco Archeologico di Ercolano and Expanded Interiors.

RW Had you not explained your rationale, I would have wondered why you chose the House of the Beautiful Courtyard, given it's so different from the Cryptoporticus. Especially as your work here is also so different to your work in Pompeii. You show a metal construction, with sheets of a modern-day material you say is called Perspex. These sheets have prints of objects on them and holes cut into them, and the construction displays physical replicas of Roman objects in different materials. Why jumble these elements together?

$\mathrm{CH}$ I am interested in how the painted, thin, linear architectural framework within the reception room projects forwards and backwards, bringing structure to this unusually large space.

RW Okay, your construction echoes the decoration of the room, but your choice of objects still seems random. Yes, you confront us with figures, but there are very few figures left depicted in these wall paintings. What did your archaeologist colleagues think about that? Weren't they concerned about context?

$\mathrm{CH}$ Well, first of all, let's consider the history of this house post-eruption. It was excavated between 1931 and 1938 by Amedeo Maiuri, an archaeologist - and at the time also the director of the sites here in the Bay of Naples from 1927 to $1961 .^{4}$ 
In 1956, Maiuri opened a small museum in this very room, presumably because it was such an unusually large space. Intent upon showing objects from the daily lives of ancient Romans, he assembled archaeological finds from all over the site. He also rearranged and posed objects in other Roman houses in order to suggest specific narratives to visitors. This approach meddled with context, and was of course controversial.

RW Wasn't it Maiuri who brought Herculaneum back to the surface of the world, who dug up our graves?

$\mathrm{CH}$ In a way, yes. He and his team did amazing work in excavating Herculaneum from 1927 onwards. One shouldn't forget, however, that this happened under a fascist regime from which Maiuri received financial support, since it was keen to exploit the Roman past for its own political propaganda and political myth-making.

RW That sounds familiar! Think of the Trojan cycle we painted at the Cryptoporticus, and how we had to highlight certain characters, certain scenes, so as to draw a connecting line between Aeneas and the mythical origins of the Roman people. We had to pay tribute to the supposed forefathers of Rome, but there was also quite a bit of subversion of theses myths going on, especially in the provinces (laughs).

$\mathrm{CH}$ I see! But let me get back to the objects we chose. There was another significant factor: When we came to Herculaneum (and Pompeii) in 2017 to scan objects, we had access to various storerooms. Consequently, we encountered these amazing wooden figures, marked by the fire, but still powerfully holding your gaze. In Herculaneum, due to the specifics of how the town was destroyed, there are still well preserved, 2000-yearold wooden statues and pieces of furniture. ${ }^{5}$ One wooden figure clearly depicted a woman with her hair in a bun, but had a raw, undefined outline. She had a strong impact upon me.

RW Ah, I see.

$\mathrm{CH}$ And then there was Livia, the wife of Augustus. Represented in silver foil, a totem of power with that laurel diadem in her hair, she demanded respect and adoration. Inadvertently, the disaster launched an iconoclastic attack on these figures. Think of what Livia has gone through, yet she is still here, bearing witness to the colossal human tragedy that unfolded here. She is even more powerful now, vulnerable, but with her integrity intact. And let's not forget Isis Lactans, an Egyptian goddess, breast-feeding her child. She is rendered in Greek style, and was probably living on a Roman house altar, together with other gods and goddesses of diverse origin. Isis Lactans is also, I would argue, a representation of empowered breast-feeding, and a very different depiction of motherhood to that of countless madonna statues which followed later.

RW Though they are not the originals, yet these figures send a shiver down my spine! I can clearly picture them in both their before and after form. But why bring these diverse figures of people and gods together? 
$\mathrm{CH}$ Working as a contemporary artist, I wasn't interested in resetting the figures in their original context. Rather I wanted to dislodge them from their historical setting and function, to question and probe them. I also wanted to focus specifically on Roman women, traditionally so much less talked about than their male counterparts. I wanted to present these Roman women as women of today. I created a plurality of images in order to probe the effect and meaning of these juxtapositions. Admittedly, some of my methods are iconoclastic, too (for example use of collage) in their brutality and occasional disregard for images. Replicating these figures through two-dimensional and three-dimensional prints in different materials tested them, but it was also an attempt at erasing them, challenging their form and their context.

RW That doesn't make sense to me. I am deeply saddened by seeing these empty, damaged houses. I feel the loss of what has been destroyed forever. There is a lot of speculation in your approach, Catrin. But it is interesting for me to look at what we had - or the meagre remains of it - through the eyes of a different century. I still don't understand why you are working at the site of a human disaster; a dug-up graveyard?

$\mathrm{CH}$ This site feels like a time capsule. You sometimes wonder whether you are in the past or the future. Your Roman wall paintings offer a different approach, in relation to questions around how to deal with a flood of images. There are also many questions raised by these ruins. How do we frame these sites? Whom do these sites serve? How should we relate to these sites now? How can we work through their meaning and significance?

RW What about that cryptic series of letters that is encoded in your installation? They seem to spell out the words 'Ciao Bella'. A joke?

$\mathrm{CH}$ No, but you could read it as a nod to the installation's almost all-female cast. I'm not spelling 'Ciao Bella'; rather I am spelling out 'Bella Ciao', the name of a partisan Italian folk song used to protest against German and Italian fascists in the last century. Including the song's title resonates with the encoded messages of Roman wall painting, and the way in which they often 'framed' houses politically. The sites at Pompeii and Herculaneum have also been framed in many different ways since their rediscovery. My nod to Bella Ciao also hints at the use of Romanità as a means of fascist propaganda. And frankly, we still need anti-fascist songs today.

RW Hmm, it's interesting that, after all these centuries, our works and remains still have political power. But how do today's Ercolano residents feel about having our graves excavated in the midst of their living-areas?

$\mathrm{CH}$ Well, what you here in Italy call the Scavi, or archaeological site, cuts right through modern Ercolano, and has made nearby communities feel marginalised. Today, the Bay of Naples is one of Italy's poorest regions, and there is a stark contrast between the poor living areas around the site, and the streams of wealthy international tourists visiting the Scavi. 
The organisations and authorities working with the Scavi are thus keen to involve local communities in the site, giving them a personal stake in it and promoting a sense of civic pride. I, too, together with my research team, have had workshops with different community groups, and in local schools. ${ }^{6}$

RW Did your exhibition at Pompeii involve the local community, too?

$\mathrm{CH}$ Well, Pompeii is very unlike Herculaneum, and is embedded in its contemporary context in a different way. Contemporary Pompeii developed more naturally around its ancient predecessor, Roman Pompeii, and is more in synch with the tourist economy. Still, Pompeii has gone through many changes recently. The Great Pompeii Project, an initiative of the Italian government funded by the European Union, has helped conserve, maintain and restore the site. And since 2014, the latest director of Pompeii has opened up the site culturally, connecting it to local and regional institutions. Expanded Interiors is part of the latter initiative. While we offered tours of the exhibition at the House of the Cryptoporticus, we didn't see the need to engage the community in the same way as at Herculaneum. ${ }^{7}$

With our conversation shifting to the Pompeiian site, the Roman wall painter and I travelled back to the House of the Cryptoporticus, where the following conversation took place two hours later:

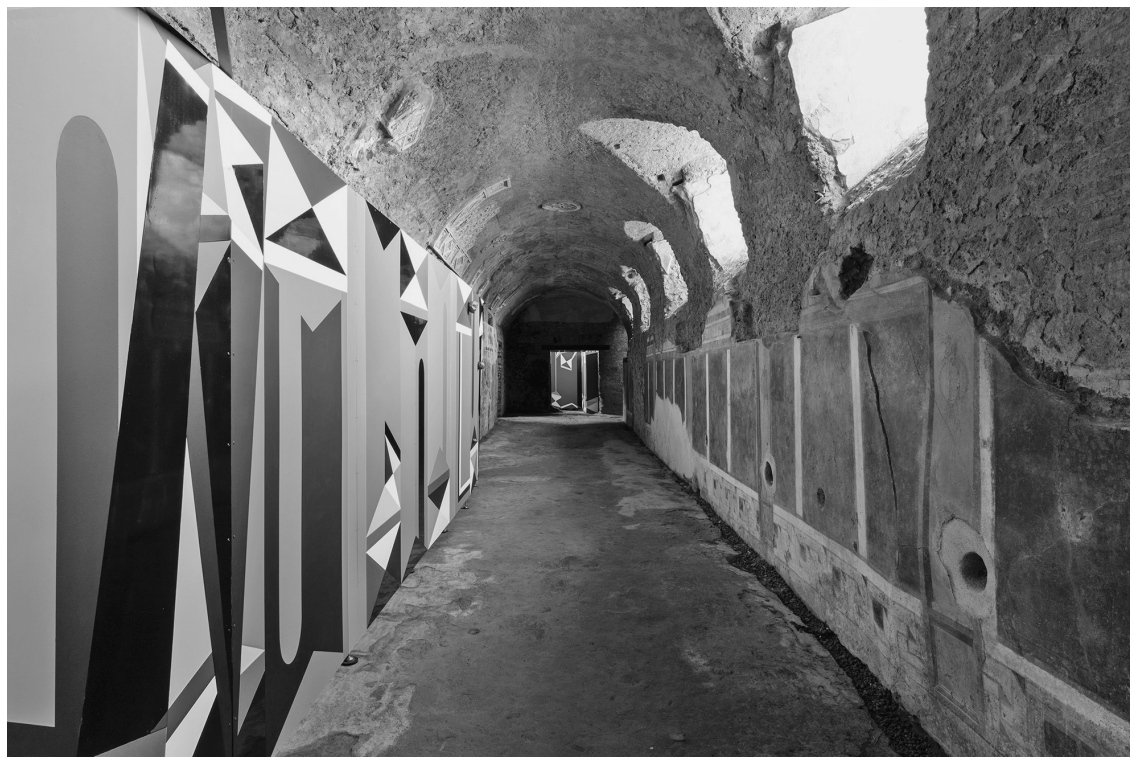

Figure 9.2 Expanded Interiors at Pompeii. Image credit: Amedeo Benestante. Courtesy of Ministero dei Beni e delle Attività Culturali e del Turismo - Parco Archeologico di Pompei and Expanded Interiors. 
RW [Again looking around the beautiful house decorated by her own workshop in antiquity.] Catrin, we have already discussed these wall paintings of mine at length. What can you tell me about your artistic response; about your installations here?

$\mathrm{CH}$ I wanted to set up a dialogue with your paintings. I was intrigued by your use of rhythm and movement, by your use of tension between actual and imagined architecture, and by the play between two-dimensional and three-dimensional space within the Cryptoporticus. Despite their irregularities and idiosyncrasies, your paintings are still orderly. Mine are more disorderly, though, their compositions almost collapsing into themselves. It is contemporary practice, after all! The composition is based on an irregular rhythm of opened and closed spaces, together with a playful, changing pattern of colour relation and function. These are paintings which fold and unfold spaces.

RW Tell me about your colour choices.

$\mathrm{CH}$ Colours are as crucial to me as they are to you, both in their own right and in relation to the room's architecture and your work. I picked up on the caput mortuum pigment used in your colonnade's back-panels, responding with a colour that's equally difficult to pin down because it sits somewhere between violet, pink, and brown. This ambiguity results in an almost 'hovering' colour that's hard to locate physically and linguistically, it's temperature largely defined by its context. For this installation, I created a cool colour environment as a juxtaposition with the mostly warm colours used within your colonnade, only picking up on the blue colours within the frieze section [...].

RW Your second installation in the small room that's aligned with the bath complex is predominantly red, a colour very much associated with our ancient practice, hence 'Pompeiian red'.

$\mathrm{CH}$ Red (like many other colours) is rich with connotation and possible interpretations. Fire. Blood. Hell. The erotic. Its political significance. ${ }^{8}$ As this installation creates its own room, I wanted it to be extremely intense with regard to both colour and composition. The composition combines sharply contrasting perspectival viewpoints: in some areas the painting seems to come out at you; in others it seems to fold around you. The perspective also shifts substantially with the movement of the viewer. I wanted this installation to make you aware of your own physicality.

Ultimately, I hoped that the remnants of your wonderful work, together with my two interventions, would create a succession of rooms, each of them impacting on the viewer very differently.

RW I can see the link to the way in which we structured houses through our decorations. However, I notice that, for all your responding to our work, you chose new materials and new techniques when executing your paintings. Were you not interested in our unique - and incredibly durable I now know - fresco techniques? 
$\mathrm{CH}$ Your techniques and processes are fascinating, but my interest in Roman wall painting doesn't lie with technique, as such. Rather it lies in the underlying principles, functions, and concepts of Roman wall painting. I am not interested in copying or illustrating your work or your techniques; rather I am trying to understand the underlying mechanisms of Roman wall painting. I am testing it, always on the lookout for new ways of utilising its principles and functions in contemporary making [...]

RW I see! It's encouraging that certain aspects of our approach might live on.

Let's now leave our woman Roman wall painter again, since we have addressed the key element of the whole Expanded Interiors project: namely the relevance of Roman wall paintings for contemporary fine-art making.

\section{Conclusion}

Expanded Interiors used contemporary fine-art practice to explore two Roman houses and their wall paintings. This unearthed a different understanding and interpretation of historical practice, and brought new perspectives on the specific Roman wall paintings in the House of the Cryptoporticus in Pompeii and the House of the Beautiful Courtyard in Herculaneum. More importantly, I would assert that this intersecting of practices reveals fresh strategies and methods for contemporary fine-art making. Those which I believe are particularly pertinent to contemporary practice are (1) the use of structural frameworks for multiple visual systems which juxtapose and build bridges between the real and the represented; (2) the use of interlocking, multiple perspectival systems that help create immersive environments, while at the same time - and paradoxically - laying bare the mechanisms to create immersive environments, hence destroying the aforementioned effects. The intersection of contemporary art and heritage sites allowed for an entanglement of practices and times. This also raised questions about making, and the resulting artworks in the past, present, and future.

My contemporary art exhibitions within the Roman houses also brought audiences a new way of experiencing the historical sites, as reflected in visitor feedback. In Herculaneum, particularly, Expanded Interiors the exhibition, together with its accompanying workshops and related events, drew in and engaged local communities. Further, we organised - together with our partners PaErco and HCP - what to our knowledge was the first workshop for local guides in the region (which resulted in PaErco and HCP setting up a focus group with the guides). We also forged new links between students from the Accademia di Belle Arti di Napoli and PaErco; the students have since been invited to perform at PaErco and have also offered on-site art laboratories for children. Further, we organised a local teacher workshop to jointly develop learning and teaching material from the Expanded Interiors research. We have since tested out this material in schools in Ercolano, and hope it will 
be used at an international level, too. These initiatives supported PaErco's and HCP's aim to give local communities more ownership of the heritage site, while also making it an integral, dynamic part of the contemporary town, and thus building closer links between Roman Herculaneum and contemporary Ercolano.

Dialogue across times, disciplines, and with local and international communities has been central to Expanded Interiors. Hence it is appropriate, in conclusion, to briefly return to our imagined panel discussion; the one in which our Roman wall painter debates practice with Lissitzky and Schwitters. At its conclusion, each artist outlines what they, personally, think is relevant for contemporary critical spatial practice. I will close this chapter with their words:

EL I believed in the socialist movement in the USSR - at least in the beginning. I wanted to shape society and pioneer alternative ways for art to infiltrate life. The artists of the twenty-first century need to get together internationally to develop a bigger, alternative vision and visual language.

KS An alternative approach, yes, but I don't see why bigger and louder is better than small and unpredicted. I believe that, today, it is more important to find ways of working that resist mainstream appropriation. It is about creating spaces that resist being repossessed by either good or bad causes - and perhaps these spaces should remain hidden and covert like those back chambers our Roman wall paintress mentioned earlier. I welcome ambiguity!

RW What Roman practice brings to this discussion is complexity, since our art articulated a whole building in a layered, yet coherent way. It also brings trust and belief in the visual and intellectual capacities of the audience, and recognises that challenging them is good. I'll close with a motto of my own: 'Complexity, difficulty, and multi-layeredness is the key to the future!'

\section{Notes}

1 Martin Blazeby, The Skenographia Project (2007), www.skenographia.cch.kcl. ac.uk.

2 Vittorio Spinazzola (ed.), Pompei alla luce degli scavi nuovi di Via dell' Abbondanza (Rome: Libreria della Stato, 1953).

3 See David Ganz and Felix Thürlemann, Das Bild im Plural: mehrteilige Bildformen zwischen Mittelalter und Gegenwart (Berlin: Dietrich Reimer Verlag, 2010).

4 For more information on Amedeo Maiuri, see Domenico Camardo and Mario Notomista (eds.), Ercolano: 1927-1961. L'impresa archeologica di Amedeo Maiuri e l'esperimento della città museo (Rome: Bretschneider, 2017).

5 During the eruption, Herculaneum was hit by a huge pyroclastic surge that reached temperatures of around $400{ }^{\circ} \mathrm{C}$. This caused the immediate death of all those who had remained in the city and the carbonisation of many organic materials. 
6 The Herculaneum Conservation Project (HCP), which has been working on-site since 2001, has done crucial conservation and protection work while also reaching out to the local community to try and give residents a renewed sense of ownership of the site. The new governing authority, the Parco Archeologico di Ercolano (PaErco), which was established in 2017, and is under the directorship of Francesco Sirano, strongly supports this agenda and has offered a range of initiatives aimed at local residents.

7 Pompeii's director Prof. Massimo Osanna has, for example, organized a joint Picasso exhibition (2017) with the Capodimonte in Naples, invited Pistoletto for an exhibition in the garden of the Palaestra (2017), and organised an exhibition in collaboration with the Madre (the contemporary art museum in Naples). The latter juxtaposed archaeological remains and contemporary artists: Pompeii@Madre. To my knowledge, Expanded Interiors was the first contemporary fine-art exhibition within an ancient Roman house at Pompeii that directly responds to the Roman remains and architecture. As such it has been used as a tester for Pompeii's plans to further integrate fine-art interventions within the site.

8 See Michel Pastoureau, Red: The History of a Colour (Princeton, NJ: Princeton University Press, 2017). 